\title{
CONTACTO ENTRE O PORTUGUÊS E O ESPANHOL: os falsos amigos nos manuais didáticos
}

Sofia Oliveira Dias

Universidade de Salamanca

\section{RESUMO}

O interesse pela investigação no âmbito do contacto linguístico entre o português e o espanhol, tanto na Europa como no Brasil, quer no que diz respeito à didática das línguas estrangeiras, quer no mundo da tradução e da lexicografia, é cada vez maior, sendo o léxico uma das áreas a destacar. Dentro desta, os, assim conhecidos, "falsos amigos" constituem um dos temas que mais interesse tem suscitado no âmbito dos estudos contrastivos entre ambas as línguas. Neste artigo é nosso objetivo analisar a presença e a apresentação dos falsos amigos nos manuais de português como língua estrangeira para hispanofalantes.

PALAVRAS-CHAVE: Português como língua estrangeira, manuais didáticos, falsos amigos.

\section{Introdução}

Durante o processo de ensino-aprendizagem de qualquer língua estrangeira (LE), o aluno vai, gradualmente, aumentando o conhecimento e domínio da língua em estudo.

Como professores de Português como Língua Estrangeira para Falantes de Espanhol (PLE-FE), constatamos, ao longo da nossa experiência docente, que uma das principais dificuldades do processo de aprendizagem sentidas pelos nossos alunos em relação à aprendizagem de vocabulário prende-se com o fenómeno da interferência da língua materna (LM) na aquisição da LE. Assim, a proximidade formal entre ambas as línguas, o português e o espanhol, atua, inicialmente, como uma vantagem para a progressão rápida do processo de aprendizagem, no entanto, 
esta mesma proximidade é responsável por um alto nível de interferência, pois acredita-se que a presença de L1 (espanhol) na produção oral e escrita em português é mais freqüente que na produção de falantes de línguas tipologicamente mais distantes. (CARVALHO, 2002, p. 599)

Para além disso, durante o processo de aprendizagem "o domínio de um outro sistema linguístico passa por diferentes fases, sendo a aquisição do léxico uma das fundamentais" (VÁZQUEZ DIÉGUEZ, 2014, p.8).

Esta constatação não é de estranhar, pois, como argumenta Corder (1994 citado em CARVALHO 2002, p. 599) "o uso freqüente de léxico pertencente a L1 na produção de uma L2 parecida provém da alta possibilidade de acerto, pois quando se trata de línguas tipologicamente mais distantes, o aprendiz arrisca menos freqüentemente". Neste sentido, Ulsh (1971 citado em ALMEIDA FILHO, 1995) quantifica que mais de 85\% do vocabulário português tem cognatos em espanhol; também Henriques (2000), no seu estudo, confirma a presença de 90\% de cognatos entre ambas as línguas. No entanto, segundo Simões e Kelm (1991 citado em CARVALHO, 2002), esse alto nível de semelhança é mais notável entre o português europeu e o espanhol peninsular e, em menor percentagem, entre o português do Brasil e o espanhol americano, que se calcula ser menor de $60 \%$.

Dentro da área de estudo do PLE-FE, Carvalho (2002) ainda se refere ao estudo de Takeuchi (1984), no qual o autor salienta que, entre as palavras que são comuns ao espanhol e ao português, as palavras que apresentam diferenças mínimas de ortografia e pronúncia, assim como os falsos cognatos, são as mais frequentes entre os desvios derivados da transferência lexical da LM. Em relação aos falsos cognatos, Laufer (1990 citado em CARVALHO, 2002, p. 600) afirma que "The tendency of the learner to associate similarity of form with similarity in meaning in L1 and L2 has been particularly noticed with speakers of languages related to L2", o que, por sua vez, explica a persistência de inúmeros falsos cognatos na produção oral e escrita dos aprendentes de português.

Por outro lado, no âmbito dos estudos contrastivos, o estudo dos falsos amigos tem suscitado um relevante número de publicações, sendo, provavelmente, o par português-espanhol o que mais atenção tem merecido, assim afirma Vásquez Diéguez (2014, p. 9):

Foram tratados [os falsos amigos] inúmeras vezes em diferentes pares de línguas, contudo, talvez seja o binómio espanhol-português um dos que mais literatura tem gerado, sendo um dos principais problemas 
lexicais com que se deparam os estudantes de língua portuguesa e espanhola ao aprenderem a língua contrária.

Em Oliveira Dias (2016), a autora constata que o interesse pelo fenómeno dos "falsos amigos" nas combinações linguísticas português-espanhol e espanhol-português surge nos anos 70 com os trabalhos de Arriola (1973) e de Schmitz (1970) e cresce significativamente a partir dos anos 90, alcançando o maior número de estudos e publicações (obras, artigos, teses de doutoramento, dissertações de mestrado, dicionários e material didático) nos últimos cinco anos. Estes são os resultados registados entre 1990 e 2015:

\begin{tabular}{|l|l|l|l|l|}
\hline $1990-1995$ & $1996-2000$ & $2001-2005$ & $2006-2010$ & $2011-2015$ \\
\hline 8 & 11 & 15 & 16 & 25 \\
\hline
\end{tabular}

(OLIVEIRA DIAS, 2016, p. 131)

Nesse estudo, confirma-se também que o interesse pelo tema não só se verifica em contextos relacionados com a tradução e a lexicografia, mas também com o processo de ensino-aprendizagem, tanto relacionado com a variante do português europeu, como com a variante do português do Brasil.

E é, precisamente, sobre falsos cognatos (VÁZQUEZ DIÉGUEZ, 2011), heterossemânticos (ALVES, 2013 e GONÇALVES, 2012), ou falsos amigos, termo próprio da Linguística Aplicada ao ensino das línguas estrangeiras (SABINO, 2006), que trata o presente trabalho.

Neste sentido, e cientes da relevância de inúmeros estudos contrastivos realizados em torno dos falsos amigos, partimos da reflexão de Carvalho (2002, p. 597) ao afirmar que "os resultados de vários estudos contrastivos entre português e espanhol fornecem base para este tipo de material didático", e empreendemos este estudo com esse propósito.

É, de facto, nosso objetivo analisar a presença e a apresentação dos falsos amigos nos manuais de PLE-FE. Para isso, partimos da definição do termo falso amigo, apresentando em seguida a metodologia usada na seleção e análise do corpus e terminando com umas breves reflexões.

\section{0 que se entende por Falso Amigo}

O fenómeno dos falsos cognatos, heterossemânticos ou falsos amigos vem sendo foco de interesse por parte de professores de LE, tradu- 
tores e lexicógrafos há quase um século. A expressão "falsos amigos" surge pela primeira vez na língua francesa "faux amis", em 1928, na obra Les faux amis ou les trahisons du vocabulaire anglais de Koessler e Derocquigny. Seguindo Durão $(2009$, p. 73$)$, confirmamos que o termo em análise foi usado pelos autores franceses para "designar um fenômeno linguístico relacionado a pares de lexias que compartilhavam uma mesma etimologia, embora tivessem acepções diferentes".

No Dicionário de Falsos Amigos do Espanhol e do Português (1992), os seus autores entendem por

Falsos Amigos aquellas palabras que por su semejanza ortográfica y/o fónica parecen a primera vista fáciles de ser entendidas, traducidas o interpretadas, pero que de hecho esconden peligrosas trampas de sentido para el incauto lector o traductor. (FEIJÓO HOYOS e HOYOS ANDRADE, 1992, p. 8)

Por sua vez, Carita (1998), na definição de falsos amigos, refere que na causa destes erros está a proximidade linguística entre as línguas. Para a autora, os falsos amigos são

aquelas palavras que, sob uma forma graficamente idêntica, muito semelhante ou foneticamente próxima, induzem frequentemente em erro o utilizador por, apesar dessa proximidade, terem significados completamente diferentes, em cada uma das línguas em análise. (Carita, 1998, p. 32)

Para ilustrar esta questão, Vaz da Silva e Vilar (2003, p. 3) definem falso amigo como "signo linguístico que, geralmente pelo efeito de partilha de uma mesma etimologia, tem uma estrutura externa muito semelhante ou equivalente a de outro signo numa segunda língua, cujo significado é completamente diferente".

Também Carlucci e Díaz Ferrero (2007, p. 168), desde o campo da tradução, entendem por falsos amigos "aquellos elementos de la lengua extranjera que poseen una forma idéntica o parecida al español y, al mismo tiempo, ocultan o disfrazan algún tipo de divergencia".

Desta forma, entendemos por "falso amigo" cada uma das unidades lexicais que, pertencendo a línguas diferentes, são formalmente (em grafia e/ou em pronúncia) semelhantes ou coincidentes, mas que diferem no significado.

\section{Análise dos manuais}

O presente estudo pretende analisar de que forma os manuais de 
PLE-FE apresentam e trabalham com os falsos amigos dentro da seleção lexical de cada um.

\subsection{Critérios de seleção}

O estudo centrou-se nos manuais de PLE-FE publicados no Brasil, em Espanha e em Portugal. Nesta primeira seleção deparamo-nos com a ausência de manuais de PLE específicos para falantes de espanhol publicados no Brasil. Assim, com o fim de suprir esta ausência, selecionámos alguns dos manuais de PLE com maior difusão e divulgação nesse país (no total cinco manuais) com o intuito de verificar se na sua elaboração os autores tiveram, de algum modo, em conta este público específico. Em Portugal encontramos um total de cinco manuais, todos da editora Lidel, dois especificamente elaborados para este público-alvo, outros dois para "falsos principiantes" e um deles elaborado como material complementar para a aula de PLE-FE. Encontramos dois métodos específicos de PLE-FE publicados em Espanha, os quais são constituídos por vários manuais.

Desta forma, o corpus é constituído por 18 manuais didáticos, editados entre 2006 e 2015 e de diferentes níveis de aprendizagem, desde o nível A1 ao nível B2, segundo o Quadro Europeu Comum de Referência para as Linguas: Aprendizagem, ensino, avaliação (QECRL). 


\section{a. Corpus}

\begin{tabular}{|c|c|c|c|c|}
\hline Manual & Autores & Data & Editores & $\begin{array}{l}\mathrm{N}^{o} \text { pág./ } \\
\text { material } \\
\text { comple- } \\
\text { mentar }\end{array}$ \\
\hline 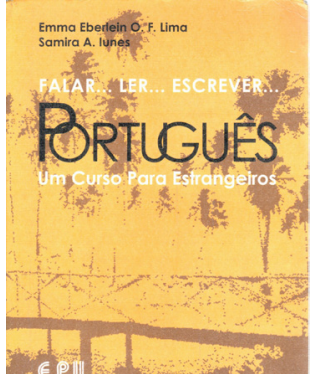 & $\begin{array}{l}\text { Emma Eberdein } \\
\text { O.F. Lima, } \\
\text { Samira A. Lunes }\end{array}$ & 2006 & E.P.U. & $\begin{array}{l}294 \mathrm{p} . \\
\text { Livro do } \\
\text { aluno, } \\
\text { Caderno de } \\
\text { exercícios, } \\
\text { CD. }\end{array}$ \\
\hline Rem- Pindo! & $\begin{array}{l}\text { Maria Harumi } \\
\text { Otuki de Ponce, } \\
\text { Silvia R.B. } \\
\text { Andrade Burim, } \\
\text { Susanna Florissi. }\end{array}$ & 2007 & $\begin{array}{l}\text { SBS } \\
\text { Editores }\end{array}$ & $\begin{array}{l}220 \mathrm{p} . \\
\text { Livro do } \\
\text { aluno, } \\
\text { Caderno de } \\
\text { exercícios, } \\
\text { CDs e } \\
\text { livro do } \\
\text { professor. }\end{array}$ \\
\hline At cer & $\begin{array}{l}\text { Emma Eberlein } \\
\text { Lima, Lutz Ro- } \\
\text { hrmann, Tokiko } \\
\text { Ishihara, Samira } \\
\text { Lunes, Cristian } \\
\text { Gonzalez }\end{array}$ & 2014 & E.P.U. & $\begin{array}{l}138 \mathrm{p} . \\
\text { Livro do } \\
\text { aluno, CDs } \\
\text { e livro do } \\
\text { professor }\end{array}$ \\
\hline
\end{tabular}




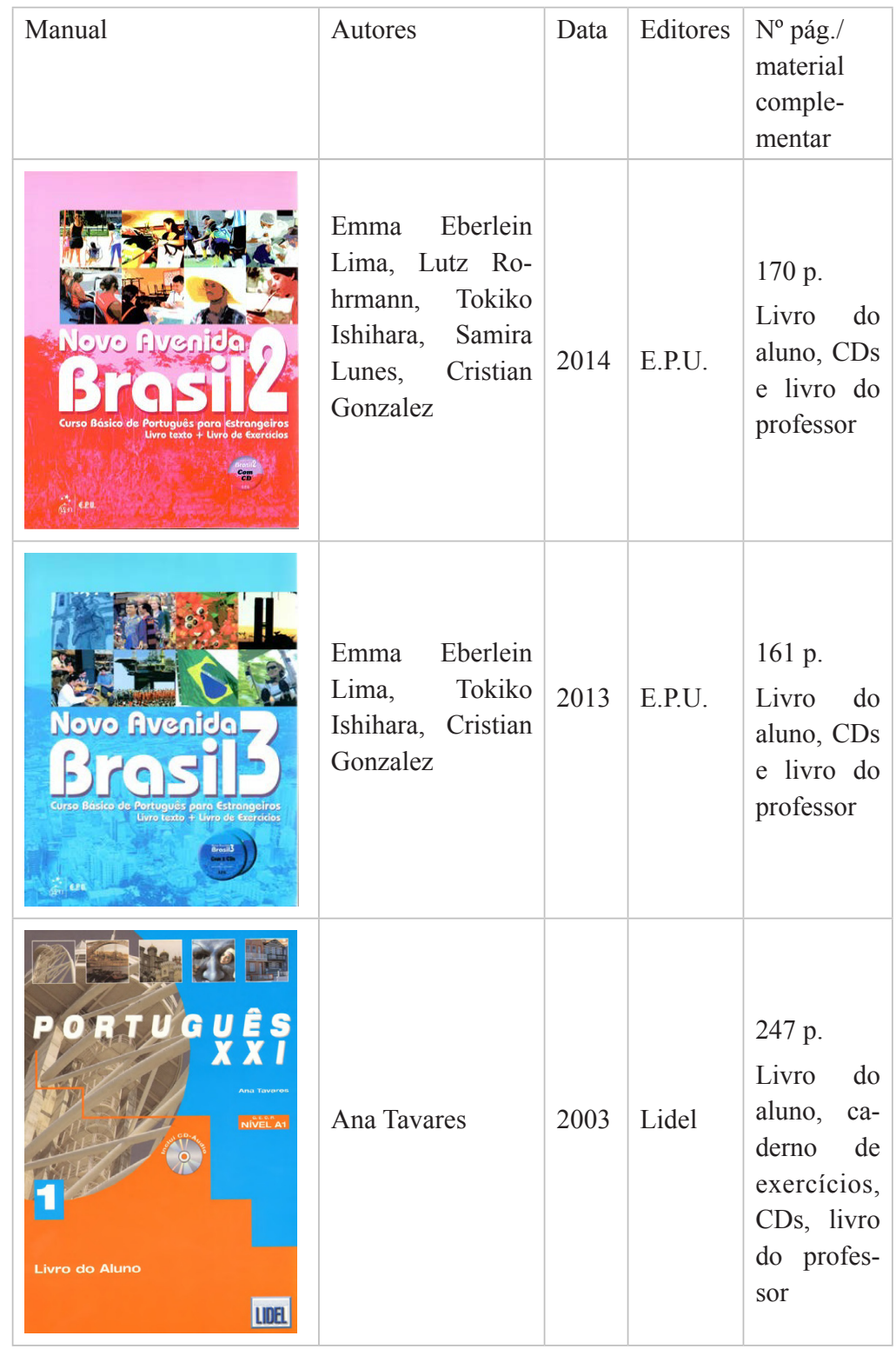




\begin{tabular}{|c|c|c|c|c|}
\hline Manual & Autores & Data & Editores & $\begin{array}{l}\mathrm{N}^{\circ} \text { pág./ } \\
\text { material } \\
\text { comple- } \\
\text { mentar }\end{array}$ \\
\hline Livro do Aluno & Ana Tavares & 2004 & Lidel & $\begin{array}{l}200 \text { p. } \\
\text { Livro do } \\
\text { aluno, } \\
\text { caderno de } \\
\text { exercícios, } \\
\text { CDs, livro } \\
\text { do profes- } \\
\text { sor }\end{array}$ \\
\hline Livro do Aluno & Ana Tavares & 2005 & Lidel & $\begin{array}{l}208 \text { p. } \\
\text { Livro do } \\
\text { aluno, } \\
\text { caderno de } \\
\text { exercícios, } \\
\text { CDs, livro } \\
\text { do profes- } \\
\text { sor }\end{array}$ \\
\hline 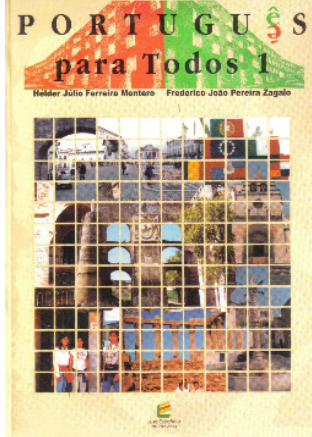 & $\begin{array}{l}\text { Hélder Júlio } \\
\text { Ferreira Montero } \\
\text { e Frederico João } \\
\text { Pereira Zagalo }\end{array}$ & 2003 & $\begin{array}{l}\text { Luso- } \\
\text {-es- } \\
\text { pañola } \\
\text { de } \\
\text { Edicio- } \\
\text { nes }\end{array}$ & $\begin{array}{l}254 \text { p. } \\
\text { Livro do } \\
\text { aluno, CD. }\end{array}$ \\
\hline
\end{tabular}




\begin{tabular}{|c|c|c|c|c|}
\hline Manual & Autores & Data & Editores & $\begin{array}{l}\mathrm{N}^{o} \text { pág./ } \\
\text { material } \\
\text { comple- } \\
\text { mentar }\end{array}$ \\
\hline $\begin{array}{l}\text { PORTUG US } \\
\text { paraTodos } 2 \\
\text { ALiti }\end{array}$ & $\begin{array}{l}\text { Hélder Júlio } \\
\text { Ferreira Montero } \\
\text { e Frederico João } \\
\text { Pereira Zagalo }\end{array}$ & 2002 & $\begin{array}{l}\text { Luso- } \\
\text {-es- } \\
\text { pañola } \\
\text { de } \\
\text { Edicio- } \\
\text { nes }\end{array}$ & $\begin{array}{l}229 \text { p. } \\
\text { Livro do } \\
\text { aluno, CD. }\end{array}$ \\
\hline 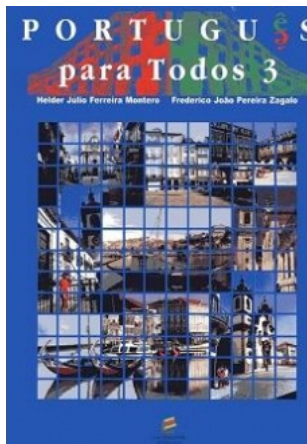 & $\begin{array}{l}\text { Hélder Júlio } \\
\text { Ferreira Montero } \\
\text { e Frederico João } \\
\text { Pereira Zagalo }\end{array}$ & 2001 & $\begin{array}{l}\text { Luso- } \\
\text {-es- } \\
\text { pañola } \\
\text { de } \\
\text { Edicio- } \\
\text { nes }\end{array}$ & $\begin{array}{l}236 \mathrm{p} . \\
\text { Livro do } \\
\text { aluno, CD. }\end{array}$ \\
\hline 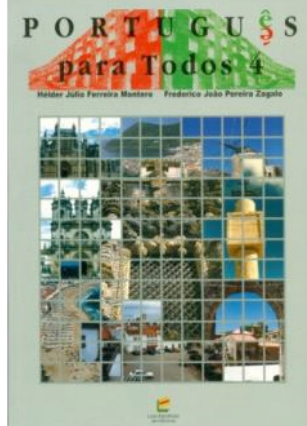 & $\begin{array}{l}\text { Hélder Júlio } \\
\text { Ferreira Montero } \\
\text { e Frederico João } \\
\text { Pereira Zagalo }\end{array}$ & 2002 & $\begin{array}{l}\text { Luso- } \\
\text {-es- } \\
\text { pañola } \\
\text { de } \\
\text { Edicio- } \\
\text { nes }\end{array}$ & $\begin{array}{l}226 \text { p. } \\
\text { Livro do } \\
\text { aluno, CD. }\end{array}$ \\
\hline
\end{tabular}




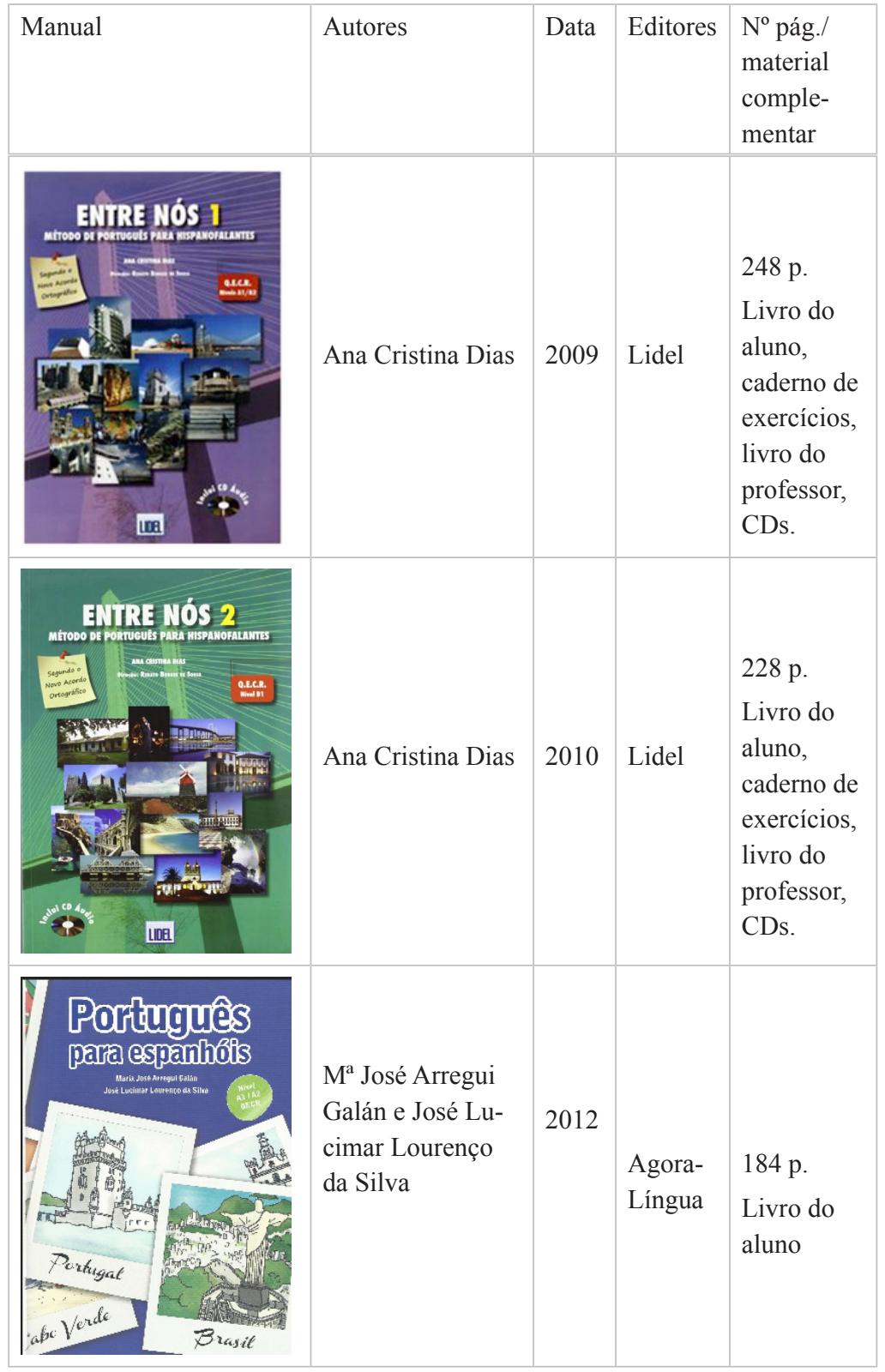




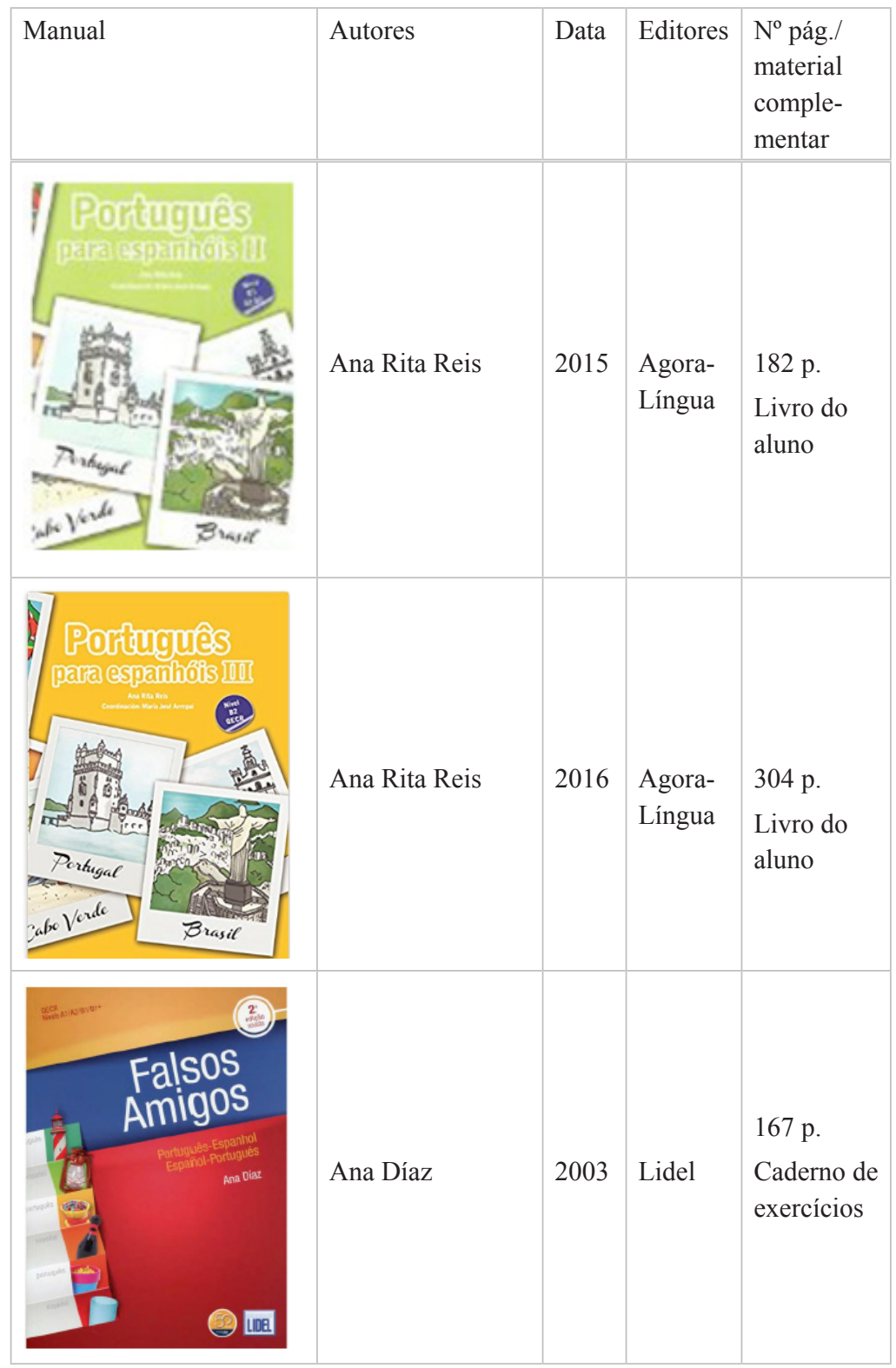




\section{Estudo: a presença dos falsos amigos em manuais didáticos}

\section{a. Manuais publicados no Brasil}

Dos manuais publicados no Brasil - Falar... Ler... Escrever... Português; Bem-vindo! e Novo Avenida Brasil -, só este último é constituído por três livros que englobam os conteúdos desde o nível básico até ao avançado. Com esta organização, os autores pretenderam aproximar os novos manuais das diretrizes do $Q E C R L$, dividindo os três volumes em três níveis: nível A1 (volume 1), Nível A2 (volume 2) e Nível B1+ (volume 3).

Todos os manuais acima referidos destinam-se a estrangeiros, adolescentes ou adultos, de qualquer nacionalidade. $\mathrm{Na}$ análise, não encontramos referência a alunos hispanofalantes, e, consequentemente, não encontramos menção a falsos amigos.

No entanto, uma análise atenta das unidades didáticas dos mesmos permitiu-nos verificar que tanto o manual Bem-vindo! como o manual Novo Avenida Brasil 2 apresentam apêndices vocabulares e secções de vocabulário específicos de cada unidade.

O manual Bem-vindo! apresenta três apêndices nas últimas páginas do livro: Apêndice 1- Alfabeto (p. 218), Apêndice 2- Gramática (p. 219) e Apêndice 3-Vocabulário (p. 220) e sete secções lexicais denominadas "Psiu!" ao longo de cada unidade didática. A maioria destas secções apresenta uma seleção de palavras relacionadas com as áreas lexicais trabalhadas na unidade. Assim, a partir do vocabulário selecionado em cada secção, o professor de PLE-FE poderá poderá trabalhar com os falsos amigos, criando exercícios específicos com os mesmos. Por exemplo, na página 9, relacionado com comidas, aparece, entre outras, a palavra "salada" [salada(pt)/ salada (es)], ou, na página 13, relacionado com legumes e verduras, aparece a palavra "legumes" [legume (pt)/ legumbre (es)].

No que respeita aos manuais Novo Avenida Brasil 1, 2 e 3, estes também apresentam um apêndice de vocabulário ordenado por ordem alfabética com todas as palavras contidas nos diálogos, exercícios, textos e explicações gramaticais. Em geral, o vocabulário aparece associado a imagens ou em listas de palavras integradas em atividades.

Tal como no caso anterior, também neste, a partir da seleção das palavras, o professor de PLE-FE poderá selecionar aquelas que são fal- 
sos amigos e realizar exercícios com os mesmos. O caso mais evidente e apropriado para trabalhar com os falsos amigos em sala de aula aparece no primeiro tema (lição) do manual Novo Avenida Brasil 2.

A lição 1 é dedicada ao corpo e o objetivo comunicativo prende-se com a descrição de pessoas e coisas. A página 73 desta lição apresenta o título "Um pouco esquisito", aparecendo nesta expressão o adjetivo "esquisito", falso amigo entre português e espanhol, e que no mesmo contexto, no Brasil, o adjetivo mais usual seria "estranho", como também aparece no próprio exercício. Veja-se o exemplo do texto:

\section{A1 1 Um pouco esquisito}

A2 Observe a ilustração e complete o texto com vocabulário de A1 e A2 do livro-texto.

Ele é um pouco esquisito. Tem sobrancelha minúscula. As são enormes como as do Mickey. Os são pequenos, mas vivos. O é feio, parece uma batata. A é grande, vai de um lado a outro do rosto. Realmente, ele é um pouco estranho, mas as mulheres gostam dele.

(ROHRMANN, ISHIHARA, LUNES e GONZALEZ, 2014, p. 73)

\section{b. Manuais publicados na Europa}

\section{i. Método Português XXI}

O método Português XXI, da autoria de Ana Tavares, sob a direção de Renato Borges de Sousa, publicado em Portugal pela editora Lidel, divide-se em três níveis de aprendizagem: A1, A2 e B1. No prefácio do manual Português XXI-Nível 1, a autora informa que o manual se destina a alunos principiantes ou falsos principiantes. Neste sentido, também no livro do professor encontramos uma referência ao perfil dos alunos, na qual os autores recomendam que, para o caso concreto de alunos espanhóis (falsos principiantes), o trabalho deverá incidir na pronúncia uma vez que a compreensão dos textos e a gramática não lhes oferece grandes dificuldades. Cada manual é constituído por 12 unidades didáticas e cada unidade contém atividades diversas, terminando sempre com um exercício fonético e um apêndice gramatical. $\mathrm{O}$ vocabulário vai sendo apresentado ao longo da unidade em atividades de associação, identificação e de completar frases. No final do livro, o aluno encontra um Glossário com a tradução para espanhol, francês, inglês e alemão. 
$\mathrm{Na}$ análise dos vários manuais, encontramos um exercício na página 195 do manual Português XXI- Nível 1 com referência aos falsos amigos. Veja-se o exemplo:

2. Algumas palavras causam problemas, porque estão muito próximas de outras que noutras línguas têm sentidos diferentes. Faça uma frase exemplificativa do significado de cada uma das palavras que se seguem. Pode usar o dicionário.

1. oficina/ escritório

2. esquisito/ raro

3. tenda/ loja

4. avariado/ roto

5. pasta/ massa

6. vestido/ robe

7. cabelo/ pêlo

8. realizar/ perceber

9. montar/ subir

(TAVARES, 2003, p. 195)

Para a realização do exercício, a autora recomenda usar o dicionário e escrever a frase, não referindo, no entanto, entre que línguas em contacto se formam os falsos amigos.

ii. Método Português para todos

O método Português para todos, da autoria de Hélder Júlio Ferreira Montero e Frederico João Pereira Zagalo, publicado em Espanha pela editora Luso-Española de Ediciones, é constituído por quatro volumes, correspondentes a quatro níveis de língua, que se estruturam de menor a maior complexidade.

Os autores não fazem referência aos níveis do $Q E C R L$, no entanto, na nota introdutória referem que o volume 1 corresponde "a la adquisición de un "nivel umbral", tal como lo define el Consejo de Europa" e o volume 2 proporciona "al alumno las situaciones comunicativas necesarias para al final del mismo haber adquirido una competencia limitada". Por sua vez, o volume 3 pretende que o aluno alcance "al final del mismo una competencia amplia" e, por último, o volume 4 "Pretende proporcionar al alumno todos los matices de la lengua oral y escrita, introdu- 
ciéndolo, al mismo tiempo, en el estudio y dominio de algunos lenguajes especificos" (FERREIRA MONTERO e PEREIRA ZAGALO, 2003, p. v). Nessa mesma nota, os autores referem que o método Português para Todos destina-se " $a$ un público heterogéneo, fundamentalmente, hispanohablante" (idem), definindo assim o seu público-alvo. Acrescentam que "La progresión de contenidos ha sido concebida en función de las dificultades inherentes al estudio del portugués (fundamentalmente) para hablantes de español, no desarrollando, por obvias, las partes del léxico, sintaxis, etc., comunes a ambas lenguas" (idem).

Cada volume é constituído por 15 unidades didáticas organizadas da seguinte forma: uma página de introdução, com a apresentação dos conteúdos comunicativos, gramaticais e lexicais da unidade; diálogos onde se introduzem os novos elementos de cada unidade; quadros morfológicos e/ou sintáticos, nos quais se apresentam as explicações dos novos elementos introduzidos nos diálogos; exercícios e/ou atividades escritas e/ou orais baseadas nas situações comunicativas e nas estruturas aprendidas; quadros informativos com a apresentação dos conteúdos teóricos, sob o título "Ajuda"; e o sumário, que aparece no final de cada unidade e onde, resumidamente, se apresenta o vocabulário, a gramática e os recursos comunicativos aprendidos na unidade didática.

Para além desta estrutura geral, cada volume termina com vários apêndices que variam ligeiramente de volume para volume. $\mathrm{O}$ apêndice com as soluções dos exercícios é comum a todos os volumes. À exceção do quarto, todos os restantes apresentam o apêndice de consolidação de conhecimentos; os volumes 2 e 3 apresentam um apêndice verbal e o volume 4 apresenta o apêndice de fonética e um apêndice sobre as "Diferenças entre o português de Portugal e do Brasil". Por último, o volume 1 apresenta um apêndice gramatical e um apêndice lexical, que só aparece unificado neste primeiro volume, uma vez que nos seguintes o novo léxico é incluído, com a respetiva tradução, em cada página da unidade didática, proporcionando as primeiras aceções de cada palavra, os falsos amigos e as diferenças de género.

Apesar da referência aos falsos amigos na nota introdutória, estes reduzem-se, no primeiro volume, ao apêndice lexical (idem, p. 227-238), no qual aparecem destacados a vermelho em português ou em espanhol. Na totalidade, registamos 103 falsos amigos na relação português-espanhol e 32 na relação inversa.

Nos volumes seguintes do método Português para todos, os auto- 
res apenas assinalam um único falso amigo entre o português e o espanhol na página 172 do volume 3: "toro $(m$. $)=$ tronco $(m$.)" (FERREIRA MONTERO e PEREIRA ZAGALO, 2001, p. 172).

\section{iii. Manual Entre Nós}

O método Entre Nós - Método de Português para Hispanofalantes, como indica o seu subtítulo, destina-se a alunos que tenham o espanhol como língua materna ou que, sendo de outras nacionalidades, tenham um bom domínio do espanhol como língua estrangeira. Este método é da autoria de Ana Cristina Dias, sob a direção de Renato Borges de Sousa, foi publicado em Portugal pela editora Lidel e é constituído por dois volumes, contemplando os níveis A1/ A2, B1, segundo o QECRL. Assim o define a autora:

No presente manual, os conteúdos e as actividades propostos a nível da oralidade e da escrita preparam o aprendente para a obtenção do CIPLE (Certificado Inicial de Português Língua Estrangeira), correspondente aos níveis A1 e A2 com as devidas adaptações ao ensino-aprendizagem de línguas próximas. (DIAS, 2009, p. 3)

Na página de apresentação do livro do professor, a autora alerta para o perfil peculiar deste público-alvo quando comparado com os saberes e as competências de alunos de outras nacionalidades:

1) Embora a aprendizagem seja favorecida pela proximidade entre as duas línguas a nível gramatical e lexical, essa mesma proximidade faz com que, muitas vezes, o aluno não se preocupe com as diferenças existentes. Tal postura conduz, regra geral, à frustração em níveis mais avançados por não se conseguir expressar corretamente; 2) A compreensão da leitura não oferece problemas. $\mathrm{O}$ aluno é capaz de ler e de interpretar textos diversos, o que o coloca num nível intermédio (B1); 3) A compreensão oral de mensagens simples é dificultada pelas diferenças existentes nos sistemas fonéticos das duas línguas; 4) A produção oral e a produção escrita são comprometidas pela interferência do espanhol. (DIAS, 2010, p. 3)

Em relação à organização geral dos manuais, cada volume é constituído por dez unidades didáticas, duas unidades de revisões intituladas "Ponto de Encontro" e dois glossários, um gramatical e outro lexical.

Por sua vez, cada unidade didática subdivide-se nas seguintes secções: "Tudo a postos?", que introduz o tema da unidade e antecipa os tópicos gramaticais e lexicais em foco; "Bússola Gramatical”, que propõe 
um estudo contextualizado e reflexivo dos conteúdos gramaticais; "Diário Lexical", que inclui textos com vocabulário relacionado com o tema em foco; "Entre Nós", que estimula a reflexão intercultural e apresenta tópicos culturais diversificados; "Cofre de sons e letras", que se centra na fonética e na ortografia; "Itinerário", que apresenta um conjunto de atividades relacionadas com o tema central; "Retrospetiva", que possibilita a revisão dos conteúdos gramaticais e/ou lexicais mais pertinentes e "Portefólio", que contém propostas de reflexão sobre o processo de aprendizagem e tarefas de escrita relacionadas com o tema da unidade" (DIAS, 2009, p.3).

No que se refere à presença de falsos amigos, no livro do professor do Entre Nós 1, a autora diz que na seç̧ão Diário Lexical "promove-se uma aprendizagem dinâmica do vocabulário relacionado com o tema da unidade e incluem-se falsos amigos" (DIAS, 2010, p. 7). Apesar de presente na elaboração do primeiro volume, já não encontramos este objetivo no volume 2, no qual se refere que a mesma secção lexical "inclui textos com vocabulário relacionado com o tema em foco. Inclui provérbios e expressões idiomáticas de uso corrente" (DIAS, 2010, p. 3).

Com estas observações, fica patente a intenção da autora em incluir no primeiro volume os falsos amigos na secção lexical. Vejamos quando e com que distribuição aparecem estes elementos no manual Entre Nós 1:

exercício 27 da secção Diário Lexical da unidade 1: a autora introduz a noção de falso amigo e propõe o primeiro exercício. "Entre o espanhol e o português existem palavras muito semelhantes, mas que têm significados diferentes. São o que chamamos falsos amigos. Encontra algum falso amigo no quadro? Em caso de dúvida pergunte: A palavras pasta não é o mesmo que...? ou A palavra pasta é um falso amigo?" (idem, p. $18)$.

exercício $\mathrm{n}^{\circ} 8$ da secção Retrospectiva da unidade 1: o aluno deve sublinhar os falsos amigos numa lista de dez palavras (idem, p. 26);

exercício $\mathrm{n}^{\circ} 31$ na secção Diário Lexical da unidade 2: o aluno deve descobrir os falsos amigos em frases relacionadas com a descrição física de pessoas (idem, p. 35);

exercício $\mathrm{n}^{\circ} 4$ da secção Retrospectiva da unidade 2: o aluno deve descobrir o falso amigo presente em cada frase (idem, p. 42);

exercício 26 da secção Diário Lexical da unidade 3: o aluno deve agrupar colunas de palavras a campos lexicais relacionados com a casa e descobrir os falsos amigos (idem, p. 50); 
exercício $\mathrm{n}^{\circ} 8$ da secção Retrospectiva da unidade 3: o aluno deve sublinhar os falsos amigos presentes numa lista de oito palavras (idem, p. 58);

exercício $n^{0} 35$ da secção Diário Lexical da unidade 4: o aluno deve descobrir os falsos amigos presentes em frases que falam sobre as tarefas domésticas (idem, p. 66);

exercício $n^{\circ} 6$ da secção Retrospectiva da unidade 4: o aluno deve descobrir o falso amigo presente em cada frase (idem, p. 74);

exercício $\mathrm{n}^{\circ} 7$ da secção Retrospectiva da unidade 5: o aluno deve dar exemplos sobre falsos amigos que pode encontrar num hotel (idem, p. 90);

exercício $\mathrm{n}^{\mathrm{o}} 13$ da secção Ponto de encontro 1: o aluno deve traduzir falsos amigos estudados e no exercício $\mathrm{n}^{\circ} 14$, o aluno deve dar mais cinco exemplos de falsos amigos (idem, p. 92);

exercício $\mathrm{n}^{0} 41$ da secção Diário Lexical da unidade 6: o aluno deve descobrir os falsos amigos presentes em frases sobre recomendações médicas (idem, p. 107);

exercício $\mathrm{n}^{\mathrm{o}} 6$ da secção Retrospectiva da unidade 7: o aluno deve identificar os falsos amigos presentes no exercício anterior (idem, p. 130);

exercício $\mathrm{n}^{\circ} 33$ da secção Diário Lexical da unidade 8: o aluno deve descobrir seis falsos amigos presentes em frases sobre conselhos para uma entrevista de trabalho (idem, p. 139);

exercício $\mathrm{n}^{\mathrm{0}} 7$ da secção Retrospectiva da unidade 8: o aluno deve corrigir "o que há de estranho" em seis frases (idem, p. 146).

Por último, nos cadernos de exercícios tanto do Entre Nós 1, como do Entre Nós 2, apesar de neste último volume não se trabalhar com falsos amigos, na ficha de autoavaliação de cada unidade didática, dentro da secção de vocabulário, aparecem duas linhas onde o aluno deve registar os falsos amigos da unidade. Para além deste espaço, no caderno de exercícios Entre Nós 1 aparecem três exercícios, nos quais o aluno deve sublinhar e identificar os falsos amigos (DIAS, 2010, p. 21 e 61).

Como já se comentou, o Entre Nós 2 não apresenta nenhum exercício com falsos amigos, em vez destes, a autora inclui provérbios e expressões idiomáticas. 


\section{iv. Método Português para Espanhóis}

Como veremos, o método Português para Espanhóis é o que apresenta um trabalho regular e constante com os falsos amigos.

O Português para Espanhóis I é da autoria de $\mathrm{M}^{\mathrm{a}}$ José Arregui Galán e José Lucimar Lourenço da Silva e o Português para Espanhóis II e o Português para Espanhóis III são da autoria de Ana Rita Reis, sob a coordenação de $\mathrm{M}^{\mathrm{a}}$ José Arregui, e todos foram publicados em Espanha pela editora AgoraLíngua.

Fica bem patente, tanto no título como no próprio prefácio do primeiro volume, que este método foi elaborado para um público com domínio da língua espanhola:

Tras 12 años de experiencia enseñando portugués a hispanohablantes, hemos podido comprobar empíricamente, alumno tras alumno, que los hablantes de español a la hora de estudiar portugués se equivocan y confunden en los mismos conceptos, consecuencia de la íntima proximidad entre ambas lenguas desde los puntos de vista semántico, ortográfico y estructural. Es decir, enseñamos las diferencias básicas entre ambas lenguas y aprovechamos las similitudes, que son muchas. (ARREGUI GALÁN, 2012, p. 3)

Como se pode comprovar, este método é constituído por três volumes, contemplando os níveis A1/A2, B1 e B2, segundo o QECRL. Diz a autora e coordenadora da edição que os dois primeiros níveis presentes no Português para Espanhóis I"se han planteado con el objetivo de alcanzar el umbral de supervivencia lingüistica y superar el portuñol" (idem), com o Português para Espanhóis II, o aluno estará "preparado para la obtención del DEPLE (Nivel B1) Título oficial reconocido a nivel internacional" (ARREGUI GALÁN, 2015, p. 3) e com o Português para Espanhóis III, o aluno estará preparado "para la obtención del DIPLE (Nivel B2) Título oficial reconocido a nivel internacional" (ARREGUI GALÁN, 2016, p. 3). No segundo volume, a autora refere que o manual segue o Novo Acordo Ortográfico e oferece ao aluno "una versión integrada entre las dos variantes: Portugués Europeo y Portugués de Brasil, haciendo hincapié en las pequeñas diferencias que existen entre ambos" (idem).

Em relação à organização geral, os dois primeiros volumes são constituídos por dez unidades temáticas, as quais se estruturam em função de quatro secções, três comuns a ambos os manuais e uma diferente. 
Enquanto as secções de "Gramática", "Comunicação" e "Análise contrastiva" são comuns; a última secção do Português para Espanhóis I é dedicada à "Fonética" e no Português para Espanhóis II é dedicada aos "Falsos amigos". Neste último volume, para além destas secções, encontramos a secção "Ortografia" na unidade didática n ${ }^{\circ} 4$ (REIS, 2015, p. 48) e a seção "Ortografia e fonética" nas unidades 5 (idem, p. 64) e 9 (idem, p. 126). Este volume, Português para Espanhóis II, conta ainda com duas unidades de revisão: unidade A (idem, p. 79-87) e unidade B (idem, p. 158-165).

Em contrapartida, o manual Português para Espanhóis III, de publicação mais recente, é constituído por doze unidades didáticas, duas unidades de revisão e três apêndices: 1) Cronologia Histórica Comum a Portugal e Espanha (REIS, 2016, p. 204-208), 2) Transcrição dos textos para compreensão oral (idem, p. 209-211), 3) Tira-dúvidas, que funciona como compêndio de gramática (idem, p. 212-247) e 4) Soluções dos exercícios (idem, p. 248-299).

Por sua vez, as doze unidades didáticas estruturam-se em seis secções de conteúdos: A. Ouvir, ler e falar; B. Vocabulário e gramática; C. Falsos Amigos; D. Ortografia e fonética; E. Expressão escrita e F. Partir à descoberta. Para além da presença de novas secções, este manual apresenta no próprio índice uma lista com os falsos amigos presentes em cada unidade.

Centrando-nos na presença e trabalho didático com os falsos amigos em cada um dos volumes comprovamos que as páginas de abertura de cada unidade didática dos volumes Português para Espanhóis II e Português para Espanhóis III contam com uma secção independente para os falsos amigos. Em contrapartida, no caso do Português para Espanhóis $I$, esta secção não existe, no entanto, os falsos amigos estão presentes na secção dedicada a "Análise Contrastiva".

Tanto no Português para Espanhóis I, como no Português para Espanhóis II, os falsos amigos são introduzidos na unidade didática através das histórias de uma personagem, cujo nome é "Cê Cedilha". Esta personagem é um agente secreto que trabalha para a Agência de Inteligência da Língua Portuguesa (ARREGUI GALÁN, 2012, p. 17) e o seu espaço tem como título "Reflexões do Cê Cedilha".

No Português para Espanhóis I, as "Reflexões do Cê Cedilha" aparecem em todas as unidades, nas seguintes páginas: $17,35,54,72,84-85$, 100-101, 117, 134-135, 150-151 e 165, com o total de 103 falsos amigos. 
No Português para Espanhóis II, a secção dos falsos amigos também se intitula "Reflexões do Cê Cedilha" e coincide com a última página de cada unidade didática, com a seguinte distribuição: páginas 19, 33, 47, 63, 78, 101, 111, 125, 143 e 157, com a apresentação de 94 falsos amigos.

Em todas as unidades didáticas, os falsos amigos são apresentados inseridos em textos escritos, aos quais se segue o seguinte exercício: "Identifique o sentido das seguintes palavras, relacionando-as com a semântica espanhola:" (idem).

No Português para Espanhóis III, a secção dos falsos amigos já não aparece associada ao "agente Cê Cedilha", aliás, neste manual já não há referência a esta personagem. Neste caso, os falsos amigos são apresentados na secção $\mathrm{C}$ com a seguinte distribuição ao longo das unidades didáticas: páginas 19-22, 39, 56, 69, 82, 101, 123, 137, 152, 169, 185 e 196, com a apresentação de 111 falsos amigos. Nas unidades 1 e 2, pede-se que o aluno utilize o falso amigo adequado ao sentido de cada frase, nas restantes unidades, o exercício proposto tem o seguinte enunciado "Complete os espaços em branco com as palavras dadas". Como se pode comprovar, os falsos amigos já não aparecem inseridos em textos a partir dos quais o aluno deduzia o significado (níveis A1/A2 e B1), agora o aluno deve conhecê-los e aplicá-los segundo o contexto.

Por último, no que se refere às unidades de revisão, verificamos que estas não contemplam nenhum exercício com os falsos amigos. A unidade de revisão A (idem, p. 104-109) apresenta dez exercícios de conteúdos gramaticais e um exercício de vocabulário e a unidade de revisão B (idem, p. 201-2013) não inclui nenhum exercício de conteúdo lexical.

\section{c. Materiais complementares}

\section{i. Manual Falsos Amigos - Português-Espanhol/ Español- Portugués}

Por último, o manual que apresentamos é totalmente dedicado ao trabalho com os falsos amigos, tal como indica o seu título. O manual Falsos Amigos é da autoria de Ana Díaz, está publicado em Portugal pela editora Lidel e contempla os níveis A1, A2, B1 e B1+ do QECRL,

Como nos indica a própria autora na introdução, este manual foi concebido como material complementar aos métodos usados nas aulas de língua portuguesa e de tradução português-espanhol, cujo 
principal objetivo é desenvolver e reforçar a competência linguística, assim como estimular o aluno para uma utilização adequada das principais ferramentas de documentação linguística, em especial os dicionários bilingues e monolingues. (DÍAZ, 2013, p. 9)

Tendo sido elaborado para falantes de espanhol, a autora alerta para as características específicas deste público-alvo:

As similitudes linguísticas entre o espanhol e o português facilitam a aprendizagem destas línguas e permitem satisfazer as necessidades comunicativas básicas do estudante num curto espaço de tempo. Este dado é uma vantagem inegável, mas pode, simultaneamente, gerar uma falsa crença de domínio linguístico e favorecer a fossilização de uma interlíngua. Além disso, a proximidade linguística entre as línguas portuguesa e espanhola pode levar a interpretar como uma similaridade aquilo que não o é, assim como originar diversas interferências e erros de tradução. (idem)

E acrescenta:

A similitude das línguas portuguesa e espanhola não se limita unicamente ao âmbito semântico; como tal, os falsos amigos não interferem apenas no significado, mas em todos os aspectos da língua. Tendo em conta esse dado, os falsos amigos podem definir-se como unidades de língua estrangeira que possuem uma forma idêntica ou parecida ao espanhol, ocultando, simultaneamente, alguma divergência que passa desapercebida e que, através de um mimetismo relativamente à língua original, provoca um erro ou lapso de compreensão ou expressão escrita ou oral. Pode verificar-se a existência de cinco grandes grupos de falsos amigos: os semânticos, os morfológicos e sintáticos; os ortográficos e ortotipográficos, os falsos amigos prosódicos e, por fim, os falsos amigos pragmáticos. Neste manual, ocupamo-nos dos falsos amigos semânticos, isto é, das unidades lexicais da língua portuguesa idênticas ou semelhantes em espanhol dotadas de um significado total ou parcialmente diferente. (idem)

O livro encontra-se dividido em três partes principais: 1. Apresentação dos falsos amigos e unidades temáticas; 2. Exercícios de revisão de conhecimentos e 3.Glossário e apêndice final que inclui as soluções dos exercícios.

Por sua vez, a primeira parte subdivide-se em três unidades principais, das quais a primeira unidade é composta por 14 unidades temáticas estruturadas por níveis de competência linguística e cujas áreas lexicais trabalhadas são as seguintes: alimentación, identificación personal y rela- 
ciones personales, enseñanza, comercio, vestuario y complementos, cuerpo humano y salud, vida animal, naturaleza, vivienda, viajes y transportes, trabajo y profesiones, lugares, valoración y calificativos, y acciones. Como comenta a autora,

No primeiro capítulo dar-se-ão a conhecer os falsos amigos, agrupados por campos semânticos de modo a facilitar a aprendizagem. Neste primeiro capítulo, fornecem-se as bases necessárias para o desenvolvimento das competências lexicais em língua portuguesa, assim como para a aprendizagem dos contextos em que as semelhanças com a língua espanhola são reais ou apenas aparentes. (idem, p. 10)

No final de cada campo semântico apresentado, encontramos exercícios com frases lacunares, cujo objetivo é preencher os espaços em branco com o falso amigo adequado e depois traduzi-lo para espanhol.

A segunda unidade deste primeiro capítulo é dedicada ao "Portugués de Brasil” (idem, p. 64-69), na qual se refere que

Algunas palabras se presentan como falsos amigos respecto al español en el portugués de Brasil, pero no en el portugués europeo o viceveersa. Otras palabras se manifiestan como falsos amigos respecto al español tanto en Brasil como en Portugal, pero tienen un significado distinto a cada lado del Atlántico. (idem, p. 64)

Ainda, a unidade 3 do primeiro capítulo é dedicada a "Conectores" (idem, p. 70-71) A autora justifica esta incorporação afirmando que os conectores

Son conjunciones, adverbios o locuciones que ponen de manifiesto una relación semántica entre los elementos de una frase. Los falsos amigos conectores pueden provocar falsos sentidos y alterar total o parcialmente el sentido de un discurso ya que son elementos que actúan de enlace en español y en portugués, pero en cada lengua tienen una función diferente. (idem, p. 70)

Por último, este capítulo encerra com a unidade 4, a qual é dedicada à "Fraseología". Nesta unidade, a autora apresenta várias unidades fraseológicas, desde provérbios, expressões idiomáticas e locuções que apresentam uma forma e significado idênticos ou semelhantes em português e espanhol. Estes falsos amigos fraseológicos podem ser totais ou parciais; os primeiros não partilham nenhum significado entre ambas as línguas e os segundos apresentam um ou vários significados comuns entre espanhol e português. 
A segunda parte é constituída por vários exercícios, cuja função é rever e praticar os conhecimentos adquiridos na primeira parte. Desta forma, encontramos os seguintes tipos de exercícios com os falsos amigos:

Campos semânticos: o aluno deve agrupar em campos semânticos as palavras dadas (idem, p. 78-79);

Sinónimos: o aluno deve substituir a palavra sublinhada por sinónimos (idem, p. 80-85);

Identificar o intruso: o aluno, com a ajuda do dicionário, deve identificar a palavra que não estabelece relação com as restantes (idem, p. 86-89);

Verdadeiro ou falso: também com a ajuda do dicionário, o aluno deve escolher a opção correta (idem, p. 90-97);

Falsos amigos em série: o aluno deve completar com as palavras adequadas de forma a relacionar diferentes falsos amigos (idem, p. 98105);

Tradução: o aluno deve traduzir para espanhol títulos de notícias (idem, p. 106-115).

A terceira e última parte foi concebida como um glossário, no qual os falsos amigos estão organizados por ordem alfabética nas combinações linguísticas português-espanhol e espanhol-português, cujo objetivo é servir de guia de consulta.

\section{Conclusões}

Neste trabalhado, realizamos uma análise sobre a presença dos falsos amigos em dezoito manuais de PLE publicados no Brasil e de PLE-FE publicados em Portugal e em Espanha.

A análise dos manuais permitiu constatar que, de certa forma, os resultados da investigação realizada no âmbito dos estudos contrastivos entre o português e o espanhol, especificamente em relação ao estudo dos falsos amigos, já tem os seus frutos na didática e, consequentemente, na sala de aula, através dos materiais usados.

Por um lado, comprovamos a presença dos falsos amigos em todos os manuais específicos para um público hispanofalante, embora com abordagens diferentes. Por outro, verificamos que nos manuais de PLE não há qualquer referência aos falsos amigos.

Esta constatação é plausível, uma vez que para trabalhar com os falsos amigos, o investigador, o autor de material didático, ou o professor, deve ter em conta as duas línguas implicadas. Para o aparecimento de um 
falso amigo, o falante-ouvinte encontrar-se-á a trabalhar com duas línguas em simultâneo. Assim, "no falso amigo dá-se sempre e obrigatoriamente uma situação de bilinguismo ou, pelo menos, de duas línguas em contacto na mente do falante" (VAZ DA SILVA e VILAR, 2003, p. 6).

Desta forma, é justificável a não inclusão dos falsos amigos nos manuais publicados no Brasil, os quais não se destinam a um público específico.

O manual Português XXI foi incluído na análise pelo facto de ter sido elaborado para "falsos principiantes", fazendo especial referência aos alunos cuja língua materna é o espanhol. Nele, os autores privilegiam a oralidade - "O Português XXI é um material que tem uma preocupação especial pelo desenvolvimento da compreensão e da expressão oral do aluno em situações reais de fala" (TAVARES, 2003, p. 3) -, área problemática no ensino-aprendizagem de PLE-FE. O único exercício encontrado, precisamente, com os falsos amigos deixa entrever uma breve preocupação com o tema.

Os manuais Português para todos são os primeiros manuais publicados na Europa especificamente para o ensino-aprendizagem de PLE-FE. Estes, quando comparados com os anteriores, avançam um pouco mais na questão dos falsos amigos, fazendo referência aos mesmos na nota introdutória e incluindo, no caso do primeiro volume, a sua listagem no apêndice lexical. Nesta seleção, os casos de falsos amigos encontrados centram-se nas palavras que apareceram ao longo das unidades didáticas, independentemente do campo lexical a que pertencem.

No caso dos manuais Entre Nós, publicados cinco anos após os anteriores, são os primeiros a apresentarem propostas didáticas para o trabalho com falsos amigos, no entanto apenas o primeiro volume reconhece um lugar privilegiado aos mesmos.

Estes elementos aparecem integrados nas secções lexicais correspondentes a cada unidade didática e, por vezes, na secção "Retrospectiva", dedicada à revisão de conteúdos das unidades. No entanto, apesar do destaque dado aos falsos amigos, verificamos que a sua presença não é homogénea em todas as unidades. Assim, os falsos amigos estão presentes nas secções "Diário lexical" e "Retrospetiva" das unidades 1, 2, 4 e 8; na secção "Diário Lexical" das unidades 3 e 6; apenas na secção "Retrospetiva" das unidades 5 e 7; e ausentes nas duas últimas unidades, 9 e 10. Por último, encontramos dois exercícios com falsos amigos no "Ponto de encontro 1", dedicado a revisões dos conteúdos das unidades anteriores. 
Em relação à diversidade de exercícios, a autora apresenta três tipos: exercícios de identificação, exercícios de correção e exercícios de tradução.

Os únicos manuais que verdadeiramente destacam a presença dos falsos amigos de forma constante e com a mesma distribuição, desde a primeira unidade até à última, são os manuais Português para Espanhóis. Nos dois primeiros volumes, os falsos amigos aparecem integrados em pequenos textos escritos, a partir dos quais o aluno deduz o significado dos mesmos em contexto. No Português para Espanhóis III, o tipo de exercício é diferente; neste, o aluno aplica os falsos amigos nos contextos adequados.

O facto de os autores manterem o mesmo tipo de exercício permite ao aluno criar uma rotina de trabalho com estas palavras: inferir significados e consultar dicionários, caso seja necessário.

Por último, o material Falsos Amigos apresenta-se como um complemento indispensável ao manual que não inclua os falsos amigos nos seus conteúdos, ou àquele em que, ainda que tendo-os em conta, seja necessário introduzir algum exercício de revisão. A grande variedade de temas, apresentados de menor a maior grau de dificuldade, assim como a diversidade de exercícios propostos (campos semânticos, sinónimos, identificar o intruso, verdadeiro ou falso, falsos amigos em série e tradução), favorecerá positivamente o conhecimento, estudo e revisão dos falsos amigos.

Em conclusão, a inclusão dos falsos amigos nos manuais de PLE-FE começou a ser, gradualmente, incrementada e valorizada nos diferentes manuais publicados tanto em Portugal como em Espanha, sendo de extrema importância que nos níveis de iniciação essa apresentação seja feita de forma progressiva, de modo a que o aluno se familiarize e incorpore tais elementos no seu conhecimento para que, em níveis mais avançados, a interferência da LM, na seleção de ditos elementos, seja menor. 


\section{CONTACT BETWEEN PORTUGUESE AND SPANISH: false friends in language textbooks}

\section{ABSTRACT}

The interest in the research on the linguistic contact between Portuguese and Spanish, both in Europe and Brazil, as far as foreign language teaching - both in the translation and lexicography areas - is concerned, has been on the increase, with lexicon being one of the most important areas. Within the latter, the so-called "false friends" are one of the elements which have led to the most significant number of studies regarding the contrastive analysis between the two languages. It is the purpose of this article to examine the presence and the presentation of false friends in the textbooks of Portuguese as a foreign language for Spanish speakers. KEYWORDS: Portuguese as a foreign language, language textbooks, false friends.

\section{REFERÊNCIAS}

ALMEIDA FILHO, José Paes. "Uma metodologia específica para o ensino de línguas próximas?” In: Almeida Filho, José Paes (Org.), Português para estrangeiros Interface com o Espanhol, Campinas: Pontes, 1995, p. 13-21.

ARREGUI GALÁN, Maria; LOURENÇO DA SILVA, José. Português para Espanhóis I. Madrid: Agoralíngua, 2012.

ARRIOLA, Paul. Portuguese and Spanish Homonyms and Homophones. Hispania, vol. 56, 2, p. 426-441, 1973.

CARITA, Lourdes. Português e Espanhol: 'falsos amigos'. In: P. FEYTOR PINTO e N. JÚDICE (coord.), Para acabar de vez com Tordesilhas, Lisboa, Colibri, p. 31-40, 1998. 
CARLUCCI, Laura; DÍAZ FERRERO, Ana María. Falsas equivalencias en la traducción de lenguas afines: Propuesta Taxonómica. Sendebar. Revista de Traducción e Interpretación, 18, p. 159-190, 2007.

CARVALHO, Ana Maria. 2002. Português para falantes de espanhol: Perspectivas de um campo de pesquisa. Hispania, 85.3, p. 597-608.

CONSELHO DA EUROPA. Quadro europeu comum de referência para as línguas: aprendizagem, ensino, avaliação. Porto: Edições Asa, 2001.

DIAS, Ana Cristina. Entre nós 1- Método de português para hispanofalantes. Livro do aluno. Lisboa: Lidel, 2009.

DIAS, Ana Cristina. Entre nós 1- Método de português para hispanofalantes. Livro do professor. Lisboa: Lidel, 2010.

DIAS, Ana Cristina. Entre nós 1- Método de português para hispanofalantes. Caderno de exercícios. Lisboa: Lidel, 2009.

DIAS, Ana Cristina. Entre nós 2- Método de português para hispanofalantes. Livro do aluno. Lisboa: Lidel, 2010.

DIAS, Ana Cristina. Entre nós 2- Método de português para hispanofalantes. Caderno de exercícios. Lisboa: Lidel, 2011.

DÍAZ, Ana. Falsos Amigos português-Espanhol/Español-Portugués. Lisboa: Lidel: 2013.

DURÃO, Adja Barbieri. "Bastidores de um dicionário de falsos amigos na direção português-espanhol”. Boletim - Centro de Letras e Ciências Humanas, vol. 57, 2009, p. 9-25.

EBERLEIN LIMA, Emma; ISHIHARA, Tokiko; GONZALEZ, Cristian. Novo Avenida Brasil 3. São Paulo: E.P.U., 2013.

EBERLEIN LIMA, Emma; ROHRMANN, Lutz; ISHIHARA, Tokiko; LUNES, Samira; GONZALEZ, Cristian. Novo Avenida Brasil 1. São Paulo: E.P.U., 2014.

EBERLEIN LIMA, Emma; ROHRMANN, Lutz; ISHIHARA, Tokiko; LUNES, Samira; GONZALEZ, Cristian. Novo Avenida Brasil 2. São Paulo: E.P.U., 2014.

FEIJÓO HOYOS, Balbina; HOYOS, Rafael. Dicionário de Falsos Amigos do espanhol e do português. São Paulo: Scritta Editorial, 1992.

FERREIRA MONTERO, Hélder Júlio; PEREIRA ZAGALO, Frederico João. Português para todos 1 - Método de Português para Estrangeiros. Salamanca: Luso-Española de Ediciones, 2003.

FERREIRA MONTERO, Hélder Júlio; PEREIRA ZAGALO, Frederico João. 
Português para todos 2 - Método de Português para Estrangeiros. Salamanca: Luso-Española de Ediciones, 2002.

FERREIRA MONTERO, Hélder Júlio; PEREIRA ZAGALO, Frederico João. Português para todos 3 - Método de Português para Estrangeiros. Salamanca: Luso-Española de Ediciones, 2001.

FERREIRA MONTERO, Hélder Júlio; PEREIRA ZAGALO, Frederico João. Português para todos 4 - Método de Português para Estrangeiros. Salamanca: Luso-Española de Ediciones, 2002.

GONÇALVES, Dania. A distância linguística influi na aquisição dos heterossemânticos? In: VII Seminário Nacional sobre Linguagens e Ensino, Pelotas, p. 333-334, 2012.

HENRIQUES, Eunice. Intercompreensão de texto escrito por falantes nativos de português e de espanhol. Delta, 16 (2), p. 263-295, 2000.

KOESSLER, Maxime; DEROCQUIGNY, Jules. Les faux amis; ou, Les trahisons du vocabulaire anglais (conseils aux traducteurs). Vuibert: Paris, 1928

LIMA, Emma Eberdeien; LUNES, Samira. Falar...Ler...Escrever...Português. Livro-texto. São Paulo: E.P.U., 2006.

OLIVEIRA DIAS, Sofia. Falsos Amigos Português-Espanhol: qual a classificação idónea para a aula de PLE?. Estudios Portugueses y Brasileños, vol.14, 2016, p.129-157

OTUKI DE PONCE, Maria Harumi; ANDRADE BURIM, Silvia; FLORISSI, Susanna. Bem-vindo!. São Paulo: SBS Editores, 2007.

REIS, Ana Rita. Português para Espanhóis II. Madrid: Agoralingua, 2015. REIS, Ana Rita. Português para Espanhóis III. Madrid: Agoralingua, 2016.

SABINO, Marilei Amadeu. Falsos Cognatos, Falsos Amigos ou Cognatos Enganosos? Desfazendo a confusão teórica através da prática. Alfa, 50 (2), p. 251263, 2006.

SCHMITZ, John Robert. Some Lexical Contrast in Spanish and Portuguese: Contrastive Analysis. Hispania, vol. 53, 4, p. 976-979, 1970.

TAVARES, Ana. Português XXI. Livro do aluno 1. Lisboa: Lidel, 2003.

TAVARES, Ana. Português XXI. Livro do aluno 2. Lisboa: Lidel, 2004.

TAVARES, Ana. Português XXI. Livro do aluno 3. Lisboa: Lidel, 2005.

VAZ DA SILVA, Ana Margarida; VILAR, Guillermo. Os falsos amigos na relação espanhol-português. Cadernos de PLE, 3, p. 75-96, 2003.

VÁZQUEZ DIÉGUEZ, Ignacio. Os falsos amigos do par espanhol-português: 
algumas reflexões históricas. Artes e Humanidades, Nº9, p. 7-31, 2014.

VÁZQUEZ DIÉGUEZ, Ignacio. Sobre algunos falsos cognados español-portugués: factores lingüísticos y sociales reflejados en la semántica. EPOS, XXVII, p. 33-48, 2011.

Recebido: 13/052018

Aceito: 14/09/2018 